\title{
Non-Suicidal Self-Injury in Adolescence: Longitudinal Associations with Psychological Distress and Rumination
}

\author{
Tinne Buelens ${ }^{1}$ (D) $\cdot$ Koen Luyckx ${ }^{1,2} \cdot$ Amarendra Gandhi $^{1} \cdot$ Glenn Kiekens $^{3} \cdot$ Laurence Claes $^{1,4}$
}

(C) Springer Science+Business Media, LLC, part of Springer Nature 2019

\begin{abstract}
Non-suicidal self-injury (NSSI) constitutes a significant mental health concern that is highly prevalent in adolescence. Theoretical accounts and empirical research suggest that, in the short-term, NSSI may provide instant relief from intense psychological distress and ruminative thoughts. However, much less is known about these associations over time throughout adolescence. Therefore, we designed a three-year longitudinal study and examined the bidirectional prospective associations between psychological distress, rumination, and NSSI. We assessed 528 secondary school students (at Time 1: Mean age $=15.0$ years, $S D=1.85$, range 11 to 19 years, $50.6 \%$ female, $98.7 \%$ of Belgian nationality) using self-report questionnaires at three annual measurement points. Cross-lagged structural equation modelling was performed to examine the directionality of associations. Results indicated positive bidirectional associations between (1) distress and NSSI; and positive unidirectional associations between (2) distress and rumination, and (3) NSSI and rumination. The current study embeds NSSI in a broader network of cognitive and emotional antecedents and consequents, and is the first to consider the long-term influence these components exert on each other. As NSSI may play a significant part in increasing distress and rumination, the behaviour potentially sustains a longer-term maladaptive cycle between emotion, cognition, and NSSI. Clinical implications of these findings are discussed.
\end{abstract}

Keywords Non-suicidal self-injury $\cdot$ Distress $\cdot$ Negative emotions $\cdot$ Rumination $\cdot$ Adolescence

Non-suicidal self-injury (NSSI) is defined as "the intentional destruction of one's body tissue without suicidal intent" (Nock and Favazza 2009, p. 9), and comprises socially unaccepted behaviours such as cutting, burning, and carving oneself (Nock 2009). NSSI typically starts in mid-adolescence (Gandhi et al. 2018; Plener et al. 2015), and approximately $17 \%$ of adolescents report having self-injured at least once (Muehlenkamp et al. 2012; Swannell et al. 2014). As NSSI

Electronic supplementary material The online version of this article (https://doi.org/10.1007/s10802-019-00531-8) contains supplementary material, which is available to authorized users.

Tinne Buelens

tinne.buelens@kuleuven.be

1 Faculty of Psychology and Educational Sciences, KU Leuven, Tiensestraat 102 - box 3720, 3000 Leuven, Belgium

2 UNIBS, University of the Free State, Bloemfontein, South Africa

3 Center for Public Health Psychiatry, KU Leuven, Leuven, Belgium

4 Faculty of Medicine and Health Sciences, University of Antwerp, Antwerp, Belgium is strongly associated with high levels of internal and interpersonal distress and an increased risk for a subsequent suicide attempt (Nock et al. 2006; Wilkinson et al. 2011), it is increasingly being recognised as an important public health issue among adolescents (Cassels and Wilkinson 2016). Compelling theoretical models posit the influence of both emotion and cognition in triggering NSSI (Hasking et al. 2017; Selby and Joiner 2009), which has led to a vast interest in the emotional and cognitive antecedents of NSSI among clinicians and researchers. Yet, up till now, few studies have considered the potential long-term emotional and cognitive consequences of NSSI (Klonsky et al. 2014). Therefore, obtaining a clearer picture of how NSSI relates to emotion and cognition over time throughout adolescence would provide valuable information from a developmental perspective. To do so, we designed the present study to investigate the directionality of associations between psychological distress, rumination, and NSSI using a three-year longitudinal design in a community sample of adolescents. Before formulating our research hypotheses, we will first consider existing research on NSSI, psychological distress, and rumination. 


\section{NSSI and Psychological Distress}

NSSI can serve varying functions for the individual (Nock and Favazza 2009). The most frequently reported function of NSSI is escaping from negative emotions (Nock and Cha 2009), a finding that received ample empirical support (for reviews, see Messer and Fremouw 2008; Taylor et al. 2017). Considering NSSI typically starts in mid-adolescence, the strong association with negative emotions is especially relevant (Gandhi et al. 2016). More specifically, the onset of adolescence is attended by increased emotional intensity and reactivity (Silvers et al. 2012). This heightened psychological distress is then supposed to be handled by emotion regulation abilities that are still maturing during early adolescence. This may increase the possibility of developing maladaptive emotion regulation strategies, such as NSSI (Alloy et al. 2016). Several studies based on self-report questionnaires have shown that NSSI is preceded by overwhelming negative feelings (Nock and Prinstein 2005) and results in a decrease of negative feelings (Franklin et al. 2010; Klonsky et al. 2014). Studies using ecological momentary assessment found that negative affect increases in the hours before and decreases immediately after engaging in NSSI (Rodríguez-Blanco et al. 2018).

Research thus converges on the immediate relief NSSI might bring to the distressed adolescent. Several studies also considered the prospective association between NSSI and psychological distress throughout adolescence. These longitudinal studies consistently reported high levels of distress being a risk factor for NSSI among adolescents (e.g., Barrocas et al. 2015; Hankin and Abela 2011; Marshall et al. 2013). For instance, one study has found self-reported depressive symptoms at the age of eight to predict self-harm 10 years later in a large community sample of boys (Haavisto et al. 2005). Similarly, self-reported internalising problems at age 12 predicted acts of deliberate self-harm three years later, at age 15 (Sourander et al. 2006). Yet, regarding the inverse relationship, it might also be that NSSI in its turn leads to increased levels of psychological distress over time. We suggest two reasons why this might be the case.

First, common NSSI methods such as cutting, carving, or burning oneself can leave permanent physical remains in the form of scars (Lewis 2016). Although scarring is often overlooked in NSSI research, some studies have shown that individuals might have serious difficulty coming to terms with NSSI scars (e.g., Hodgson 2004). For instance, Lewis and Mehrabkhani (2016) found nearly half of their sample of individuals with NSSI to express feelings of abhorrence, shame, or disgust towards the scars on their body. Feeling disgusted or ashamed regarding NSSI scars on one's body may also be associated with a poorer body image (e.g., Muehlenkamp and Brausch 2012). For instance, Ross and colleagues (Ross et al. 2009) provided evidence that, regardless of gender, those with NSSI reported greater body dissatisfaction than controls. Thus, via shame, disgust, or poor body image, NSSI and the accompanying scarring can lead to increased psychological distress over time.

A second possible explanation for NSSI leading to distress lays in poor emotion regulation abilities. Namely, a recent longitudinal study reported that NSSI can be considered as a risk factor for poorer emotion regulation skills one year later (Robinson et al. 2018). Speculatively, engaging in NSSI might prevent adolescents from learning more adaptive emotion regulation strategies to downplay negative affect, leading to an increased sensitivity to negative emotions. Some prospective studies have indeed reported a bidirectional association between self-harm and depressive symptoms (Lundh et al. 2011b) and between self-harm and psychological problems (Lundh et al. 2011a). It should be noted that these findings are to be considered tentatively given the use of the term deliberate self-harm in Lundh's studies, which significantly differs from NSSI by not explicitly excluding suicidal intentions. In sum, adding to the established finding of distress leading to NSSI, emerging research now suggests that, over time, NSSI might be associated with increased psychological distress.

\section{NSSI and Rumination}

Additionally, recent models have added a cognitive component to the distress-NSSI link. For instance, the Emotional Cascade Model for NSSI (ECM-NSSI; Selby et al. 2008) includes rumination as a cognitive component next to distress to explain NSSI. Rumination is defined as the continuous thinking about symptoms, causes, and consequences of a negative emotional experience (Nolen-Hoeksema et al. 2008). It has been theorised that rumination becomes more apparent in early adolescence due to cognitive development and increased exposure to stressful life events in this developmental period (Davey et al. 2008; Jose and Brown 2008). Furthermore, research has repeatedly shown that rumination maintains or worsens depressive symptoms and negative emotions, by facilitating recall of negative events (Hankin and Abramson 2001). This idea is also reflected in the ECM-NSSI, which states that rumination increases negative emotions, and vice versa. This process results in an intense self-amplifying emotion-rumination cycle or emotional cascade. NSSI may interrupt the emotional cascade by shifting the focus away from negative emotions/thoughts towards physical sensations associated with NSSI.

Several cross-sectional studies have provided evidence for different components of the ECM-NSSI model. First, positive correlations have been frequently reported between rumination and negative emotions (for reviews, see Nolen-Hoeksema et al. 2008; Thomsen 2006). For instance, Donaldson and Lam 
(2004) asked participants to focus their attention on a series of statements designed to promote ruminative thoughts. This experimental induction of rumination significantly increased the participants' self-reported depressive feelings. Moreover, rumination made negative emotions linger on: the more attention one devoted to a negative stimulus, the longer one experienced negative emotions (Thomsen 2006; McIntosh 1996). Although still somewhat scarce, the majority of prospective studies in community samples have found positive reciprocal associations between rumination and negative emotions or distress (Abela and Hankin 2011; Hilt et al. 2010; Jose and Weir 2013; Thomsen 2006). This suggests that rumination predicts increased distress and, vice versa, distress predicts increased rumination.

Second, cross-sectional evidence was reported for the link between rumination and NSSI (e.g., Armey and Crowther 2008; Selby and Joiner 2009). In a sample of undergraduate students, Selby and colleagues (Selby et al. 2010) found that rumination significantly predicted the frequency of NSSI. Likewise, Hoff and Muehlenkamp (2009) revealed that college students with a history of NSSI reported significantly more rumination than controls without NSSI. Additionally, some longitudinal studies have been conducted to investigate whether rumination predicts NSSI over time, but the reported results are mixed (Barrocas et al. 2015). On the one hand, Selby and colleagues (Selby et al. 2013) found trait rumination to prospectively predict the daily number of NSSI episodes in adults and Bjärehed and Lundh (2008) showed rumination being a predictor of self-harm in 14-year-olds. On the contrary, rumination did not significantly predict the longitudinal course of NSSI in an eight-wave study on Chinese adolescents (Barrocas et al. 2015). Furthermore, as far as we are aware, no study considered the inverse association (i.e., the possibility that NSSI might also be associated with increased rumination over time). Specifically, if NSSI leads to feelings of shame (Mahtani et al. 2018; Stänicke et al. 2018) and impaired interpersonal relationships (Burke et al. 2015; Robinson et al. 2018), it might be that adolescents who engage in NSSI show an increase in ruminative thoughts over time.

Therefore, to provide insight in the longer-term directionality of associations between psychological distress, rumination, and NSSI in adolescents, longitudinal research using an integrative framework is needed.

\section{Hypotheses}

To address these gaps in the existing literature, the present study examines the directionality of effects between psychological distress, rumination, and NSSI using a three-year longitudinal design in a community sample of adolescents. Concerning the relationship between psychological distress and rumination, we expected distress and rumination to positively predict one another over time (Thomsen 2006). With respect to the association between distress and NSSI, we hypothesised that engaging in NSSI may predict distress and that distress may predict NSSI over time (Klonsky et al. 2014; Nock and Prinstein 2005). Finally, regarding the temporal relation between rumination and NSSI, it was difficult to formulate clear hypotheses due to the paucity of prior longitudinal research. Taken together, we hypothesised bidirectional positive associations between (1) distress and rumination and (2) distress and NSSI, and had no clear hypotheses concerning the temporal pathway between (3) rumination and NSSI.

\section{Method}

\section{Participants and Procedure}

The current longitudinal study consisted of three annual measurement points with one year intervals and was part of a larger data collection (Gandhi et al. 2017). At Time 1 (T1), the sample consisted of 528 students $(50.6 \%$ female) between the ages of 11 and $19(M=15.0 ; S D=1.85)$. At Time $2(\mathrm{~T} 2)$, 384 adolescents $(M=15.53 ; S D=1.68 ; 53.4 \%$ female $)$ and at Time 3 (T3), 326 students $(M=16.30 ; S D=1.61 ; 55.2 \%$ female) participated. A total of 312 students participated on all three measurement points. Data were collected in a secondary school in a Dutch speaking, middle class suburb of Belgium. The vast majority of participants $(98.7 \%$ at T1) identified as Belgian.

All students of the secondary school were invited via a letter addressed to them and their parents. Out of the 1115 contacted students, 528 students agreed to partake $(47.35 \%$ response rate). All of them received active parental informed consent beforehand. The study took place during school hours, with the researchers present at all time. Each student received an informed consent form, the questionnaire booklet and an envelope. After filling out the informed consent form and all questionnaires, the students returned them in a sealed envelope to the researchers. At each time point, the students received a movie ticket as compensation. Students who by T2 and T3 had left school were contacted by e-mail to complete the online version of the informed consent form and questionnaire booklet. A unique code was assigned to each student and was used throughout the entire study to ensure anonymity. The study was approved by the Ethics Committee at the University of Leuven.

\section{Measures}

Non-suicidal Self-Injury At T1, NSSI was assessed using a single-item, dichotomous measure: 'Have you ever engaged in self-injury without an intent to die?' (yes/no). At T2 and T3, 
the item was altered into 'Have you engaged in self-injury without an intent to die since the previous survey?' (yes/no). Thus, lifetime prevalence of NSSI was measured at T1 and 12-month prevalence of NSSI was measured at T2 and T3.

Psychological Distress The Hospital Anxiety and Depression Scale (HADS; Zigmond and Snaith 1983) is a valid and reliable assessment tool for psychological distress in community samples of adolescents (Chan et al. 2010; White et al. 1983). The scale consists of 14 items measuring both anxiety and depression (seven items each). Participants responded to the items using a 4-point Likert scale ranging from 0 (Hardly at all) to 3 (Definitely). Sample items are: 'I still enjoy the things I used to enjoy' (opposite for depression) and 'I feel tense or 'wound up' (for anxiety). A confirmatory meta-analysis (Norton et al. 2013) has shown that the HADS can be best considered to be one-factorial ${ }^{1}$ and to measure general psychological distress. In the present study, Cronbach's alpha for the total HADS ranged between 0.80 and 0.87 at T1-3.

Rumination The rumination subscale of the RuminationReflection Questionnaire (RRQ; Trapnell and Campbell 1999) was used to assess rumination. This scale consists of 12 items to be rated on a 5-point Likert scale, ranging from 1 (Strongly disagree) to 5 (Strongly agree). A sample item is: "Sometimes it is hard for me to shut off thoughts about myself". The rumination subscale's Cronbach's alpha ranged between 0.86 and 0.89 at T1-T3.

\section{Analytical Strategy}

We used multiply imputation to handle missing data at followup (Rubin 2004). We created 100 multiply imputed datasets (Carlin 2015) using Markov Chain Monte Carlo sequence (convergence value was set to 0.001 ) and unrestricted variance covariance technique. This state of the art missing data handling increases the power of our analyses and avoids biased estimates that would be obtained with conventional missing data handling strategies (i.e., list-wise deletion, means substitution; Rubin 2004). Multiply imputed datasets were generated using Mplus (v7.4; Muthén and Muthén 2012), resulting in a final data set with 528 participants at each wave (which equals the number of participants at T1).

Cross-lagged analysis using a structural equation modelling approach was adopted to investigate directionality of effects. This technique estimates three different types of relations among the study variables. First, the within-time

\footnotetext{
${ }^{1}$ Additionally, we performed confirmatory factor analysis (CFA) on HADS at T1 and examined measurement invariance of the one-factor solution of the HADS. In the CFA, the two-factor structure did not converge and HADS met partial scalar measurement invariance. Based on these results, we retained the more parsimonious one-factor HADS structure in the current study.
}

association refers to the relation between two variables measured at the same time. These concurrent correlations are referred to as initial associations at the first measurement point (T1), but can be interpreted as correlated relative change at follow-up measurements (i.e., T2 and T3 in the present study; Klimstra et al. 2010). Second, the autoregressive or stability path refers to the prediction of a variable at $\mathrm{T} 2 / \mathrm{T} 3$ by this same variable at T1/T2. Finally, the cross-lagged path refers to the prediction of a variable at $\mathrm{T} 2 / \mathrm{T} 3$ by another variable at $\mathrm{T} 1 / \mathrm{T} 2$ (Anderson and Kida 1982; Kline 2005). The model tested is shown in Fig. 1. The within-time associations at T1 to T3 (initial associations $\mathrm{a}_{1}-\mathrm{a}_{3}$ and correlated relative change associations $\left.a_{4}-a_{9}\right)$ and all autoregressive pathways $\left(b_{1}-b_{6}\right)$ were included along with the cross-lagged pathways $\left(\mathrm{c}_{1-2}, \mathrm{~d}_{1-}\right.$ $\left.{ }_{2}, \mathrm{e}_{1-2}, \mathrm{f}_{1-2}, \mathrm{~g}_{1-2}, \mathrm{~h}_{1-2}\right)$. We used the weighted least squares means and variance adjusted (WLSMV) estimation procedure to take into account the inclusion of categorical and continuous variables in our model (Muthén and Muthén 2017). Linear regression coefficients were estimated for the continuous dependent variables (i.e., distress and rumination) and probit regression coefficients were estimated for the categorical variables (i.e., absence/presence of NSSI). Age and gender were included as potential covariates. To make the baseline model more parsimonious, we tested whether paths could be constrained equal across time. Specifically, Wald's test (Harrell 2001) was used to test whether standardised coefficients of correlated change (i.e., $a_{4}=a_{7}, a_{5}=a_{8}, a_{6}=a_{9}$ ), stability paths (i.e., $b_{1}=b_{2}, b_{3}=b_{4}, b_{5}=b_{6}$ ), and cross-lagged paths (i.e., $c_{1}=c_{2}, d_{1}=d_{2}, e_{1}=e_{2}, f_{1}=f_{2}, g_{1}=g_{2}, h_{1}=h_{2}$ ) could be constrained equal across time.

Fit of the individual models was evaluated using a combination of following model fit indices: a) $\chi^{2}$ test - a smaller, non-significant value is preferred; $b$ ) the root mean square error of approximation (RMSEA) - a value less than 0.08 indicates an acceptable fit; and c) the comparative fit index (CFI) and Tucker-Lewis index (TLI), a value greater than .90 indicates acceptable fit (Brown 2015). All the fit indices and coefficients reported in the results section are an average of 100 multiply imputed datasets.

\section{Results}

Missingness Using two separate logistic regression models, we investigated if missingness at T2 and T3 was associated with variables of interest measured at the preceding data collection waves. Percentages of missing responses across the variables at each time-point are provided in Table 1. The logistic regression models indicated that missingness at $\mathrm{T} 2$ was positively associated with age (Beta [S.E.] $=0.66[0.08]$, Wald's statistic $[\mathrm{df}=1]=75.17, p<0.001, \mathrm{OR}=1.94)$. The remaining variables included in the model were not significantly associated with drop-out at T2. At T3, drop-out was positively predicted by age (Beta $[$ S.E. $]=0.41[0.10]$, 
$\mathrm{T} 1$

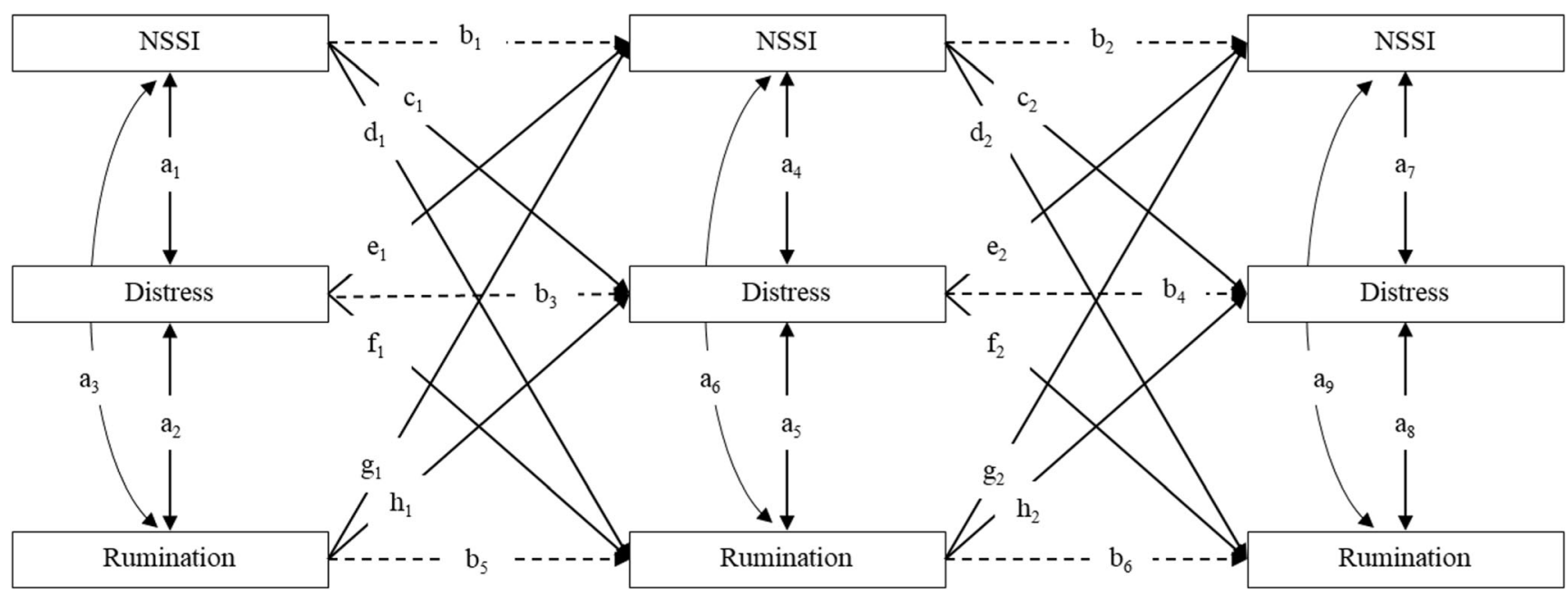

Fig. 1 Cross-lagged model tested in the present study with initial associations $\left(a_{1}-a_{3}\right)$, correlated relative change $\left(a_{4}-a_{9}\right)$, one-year relative stability paths $\left(b_{1}-b_{6}\right)$, and cross-lagged paths in the first time interval $\left(c_{1}-\right.$

Wald's statistic $[\mathrm{df}=1]=17.08, \mathrm{p}<0.001, \mathrm{OR}=1.51$ ). Additionally, males had higher odds of dropping out at T3 than females (Beta [S.E.] $=0.80$ [0.32], Wald's statistic [df = $1]=6.25, p=0.012, \mathrm{OR}=2.22)$. The main study variables (measured at T1 and T2) were not associated with an increased probability of dropping out from the study at $\mathrm{T} 3$. Given that missingness at T2 and T3 was only related to auxiliary variables, the assumption of missingness at random (MAR) seemed tenable.

Descriptives Lifetime prevalence of NSSI at T1 was around $13.8 \%$ and 12 month-prevalence at $\mathrm{T} 2$ and $\mathrm{T} 3$ was $7.6 \%$ and $9.3 \%$, respectively. At T1, lifetime prevalence of NSSI significantly increased with age $\left(F_{\text {welch }}(1,111)=13.71, p<0.001\right)$ and was significantly higher in girls $(n=54,25 \%)$ compared to boys $\left(n=19,7 \% ; \chi^{2}{ }_{1}=18.56, p<0.001\right){ }^{2}$ Table 2 displays descriptive statistics and correlation coefficients among all study variables. Over all three measurement points, correlations between NSSI and distress ranged from 0.25 to 0.52 $(p<0.001)$, correlations between NSSI and rumination ranged from 0.21 to $0.40(p<0.001)$, and correlations between distress and rumination ranged from 0.38 to $0.69(p<0.001)$.

Cross-Lagged Analysis The baseline model had an acceptable fit $\left(\chi^{2}=44.97(S D=10.16), d f=18\right.$; RMSEA $=0.05(S D=$ $0.01)$; CFI: $0.98(S D=0.01)$; TLI $=0.95(S D=0.02)$ ). Wald's test indicated that one correlated relative change path $\left(\mathrm{a}_{4}\right.$ with $\mathrm{a}_{7}$; Wald's statistic $\left.[d f=1]=4.16, p=0.04\right)$ and one cross-lagged path $\left(\mathrm{d}_{1}\right.$ with $\mathrm{d}_{2}$; Wald's statistic $[d f=1]=5.21$,

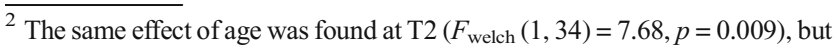
not at $\mathrm{T} 3(F(1,322)=1.38, p=0.241)$.
}

$\left.\mathrm{h}_{1}\right)$ and the second time interval $\left(\mathrm{c}_{2}-\mathrm{h}_{2}\right)$. The $\mathrm{T} 1 \rightarrow \mathrm{T} 3$ paths were not tested in the current study

$p=0.02$ ) could not be constrained equal. The more parsimonious model, which constrained all other tested parameters while freeing $a_{4}-a_{7}$ and $d_{1}-d_{2}$, had an acceptable fit $\left(\chi^{2}=\right.$ $77.24(S D=12.28), d f=28$; RMSEA $=0.06(S D=0.01)$; $\mathrm{CFI}=0.97(S D=0.01) ; \mathrm{TLI}=0.94(S D=0.02))$. Therefore, this model was used to examine the directionality of effects between the study variables.

Figure 2 presents the standardised estimates averaged over 100 imputed datasets. ${ }^{3}$ Bidirectional associations at both oneyear intervals were found between distress and NSSI: Distress at $\mathrm{T} 1 / \mathrm{T} 2$ positively predicted NSSI at $\mathrm{T} 2 / \mathrm{T} 3$ and, vice versa, NSSI at T1/T2 positively predicted Distress at T2/T3. Furthermore, results showed a unidirectional association at both intervals between Distress and Rumination: Distress at $\mathrm{T} 1 / \mathrm{T} 2$ positively predicted Rumination at T2/T3. Finally, a unidirectional association at the second, but not the first interval was found: NSSI at T2 positively predicted Rumination at T3. All stability paths were significant at the 0.001 level across the studied two-year period. At $\mathrm{T} 1$, all within-time associations were significant and positive. At $\mathrm{T} 2$ and $\mathrm{T} 3$, all relative correlated change paths were significant and positive too, with the exception of the non-significant relation between NSSI and Distress at $\mathrm{T} 2$.

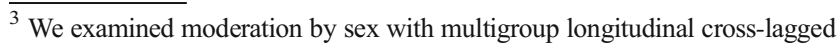
models. Due to the lower number of males engaging in NSSI in our sample, these findings should be interpreted tentatively. However, our results showed that the fit of the model with equally constrained mediation across males and females was similar to the fit of the unconstrained gender mediation model (i.e., constrained model fit: $\chi^{2}=82.53$; RMSEA $=0.07$; CFI $=0.97$; TLI $=0.92$ and unconstrained model fit: $\chi^{2}=77.24$; RMSEA $=0.06$; CFI $=0.97$; TLI $=0.94)$. This suggests that the strength of the reported associations is similar between males and females.
} 
Table 1 Percentages of missing responses across the variables at each time-point

\begin{tabular}{lllll}
\hline & & T1 & T2 & T3 \\
\hline \multirow{2}{*}{ NSSI } & Sample size & 528 & 382 & 324 \\
\multirow{2}{*}{ Distress } & Missing responses (\%) & $0(0 \%)$ & $146(27.65 \%)$ & $204(38.64 \%)$ \\
& Sample size & 528 & 354 & 320 \\
\multirow{2}{*}{ Rumination } & Missing responses (\%) & $0(0 \%)$ & $174(32.95 \%)$ & $208(39.39 \%)$ \\
& Sample size & 528 & 370 & 321 \\
& Missing responses (\%) & $0(0 \%)$ & $158(29.92 \%)$ & $207(39.20 \%)$ \\
\hline
\end{tabular}

\section{Discussion}

The present study investigated the directionality of effects among psychological distress, rumination, and NSSI using a three-year longitudinal design in a community sample of adolescents. As expected, cross-lagged path analysis indicated a bidirectional association between distress and NSSI over time. Partially confirming our hypotheses, unidirectional associations were found between psychological distress and rumination, and between rumination and NSSI.

\section{NSSI and Psychological Distress}

In line with expectations, cross-lagged analyses indicated a bidirectional positive association between psychological distress and NSSI over time. This bidirectional relationship suggests that adolescents might engage in NSSI as a result of psychological distress and, critically, by doing so, may further increase their distress over time. These associations were also reflected in the correlated change analyses, which showed that increases in distress were related to increases in NSSI. These findings are in line with previous longitudinal studies that consistently reported psychological distress as a prospective risk factor for NSSI among adolescents (e.g., Barrocas et al. 2015). Additionally, longitudinal studies on self-harm, a concept related to but different from NSSI by not explicitly excluding suicidal intent, found evidence for the inverse relationship as well (i.e., self-harm as a prospective risk factor for depressive symptoms; Lundh et al. 2011a, b). To the best of our knowledge, the current study is the first to report NSSI as a risk factor for future distress among adolescents. Although it is theoretically and clinically meaningful to detect the influence of NSSI on future psychological distress, the cross-lagged analysis used in the current study only allows us to describe (rather than explain) this association. Therefore, future longitudinal studies should investigate possible mechanisms through which NSSI creates subsequent distress. We briefly suggested two mechanisms in the introduction.

First, we posited resentfulness over remaining scars as a possible explanation of NSSI leading to self-hatred or disgust and thus distress over time (Lewis 2016; Lewis and Mehrabkhani 2016). Added hereupon, scars might impair the adolescent's social life. As NSSI is a highly stigmatised behaviour that is often interpreted as attention-seeking, parents and peers might react to the adolescent's NSSI and scars
Table 2 Descriptive statistics of NSSI engagement, Distress (range 06) and Rumination (range 1-5) and correlations among the study variables. For NSSI, the percentage and frequency of those engaging in the behaviour is reported. For Distress and Rumination, the mean score and standard deviation are provided

\begin{tabular}{|c|c|c|c|c|c|c|c|c|c|c|}
\hline & & $\% / M(S D)$ & 2 & 3 & 4 & 5 & 6 & 7 & 8 & 9 \\
\hline 1. & NSSI T1 & $13.8 \%(n=73)$ & $0.45 * * *$ & $0.29 * * *$ & $0.32 * * *$ & $0.25^{* * *}$ & $0.36^{* * *}$ & $0.37 * * *$ & $0.23 * * *$ & $0.25 * * *$ \\
\hline 2. & NSSI T2 & $7.6 \%(n=29)$ & & $0.35 * * *$ & $0.34 * * *$ & $0.34 * * *$ & $0.31 * * *$ & $0.24 * * *$ & $0.21 * * *$ & $0.26^{* * *}$ \\
\hline 3. & NSSI T3 & $9.3 \%(n=30)$ & & & $0.29 * * *$ & $0.28 * * *$ & $0.52 * * *$ & $0.22 * * *$ & $0.22 * * *$ & $0.40 * * *$ \\
\hline 4. & Distress T1 & $1.56(0.79)$ & & & & $0.63 * * *$ & $0.57 * * *$ & $0.57 * * *$ & $0.38 * * *$ & $0.40 * * *$ \\
\hline 5. & Distress T2 & $1.55(0.79)$ & & & & & $0.67 * * *$ & $0.38 * * *$ & $0.60 * * *$ & $0.47 * * *$ \\
\hline 6. & Distress T3 & $1.56(0.88)$ & & & & & & $0.44 * * *$ & $0.51 * * *$ & $0.69 * * *$ \\
\hline 7. & Rumination $\mathrm{T} 1$ & $3.23(0.81)$ & & & & & & & $0.59 * * *$ & $0.53 * * *$ \\
\hline 8. & Rumination $\mathrm{T} 2$ & $3.25(0.83)$ & & & & & & & & $0.68 * * *$ \\
\hline 9. & Rumination T3 & $3.24(0.82)$ & & & & & & & & - \\
\hline
\end{tabular}

NSSI, Non-suicidal self-injury

$* p<0.05 ; * * p<0.01 ; * * * p<0.001$ 
$\mathrm{T} 1$

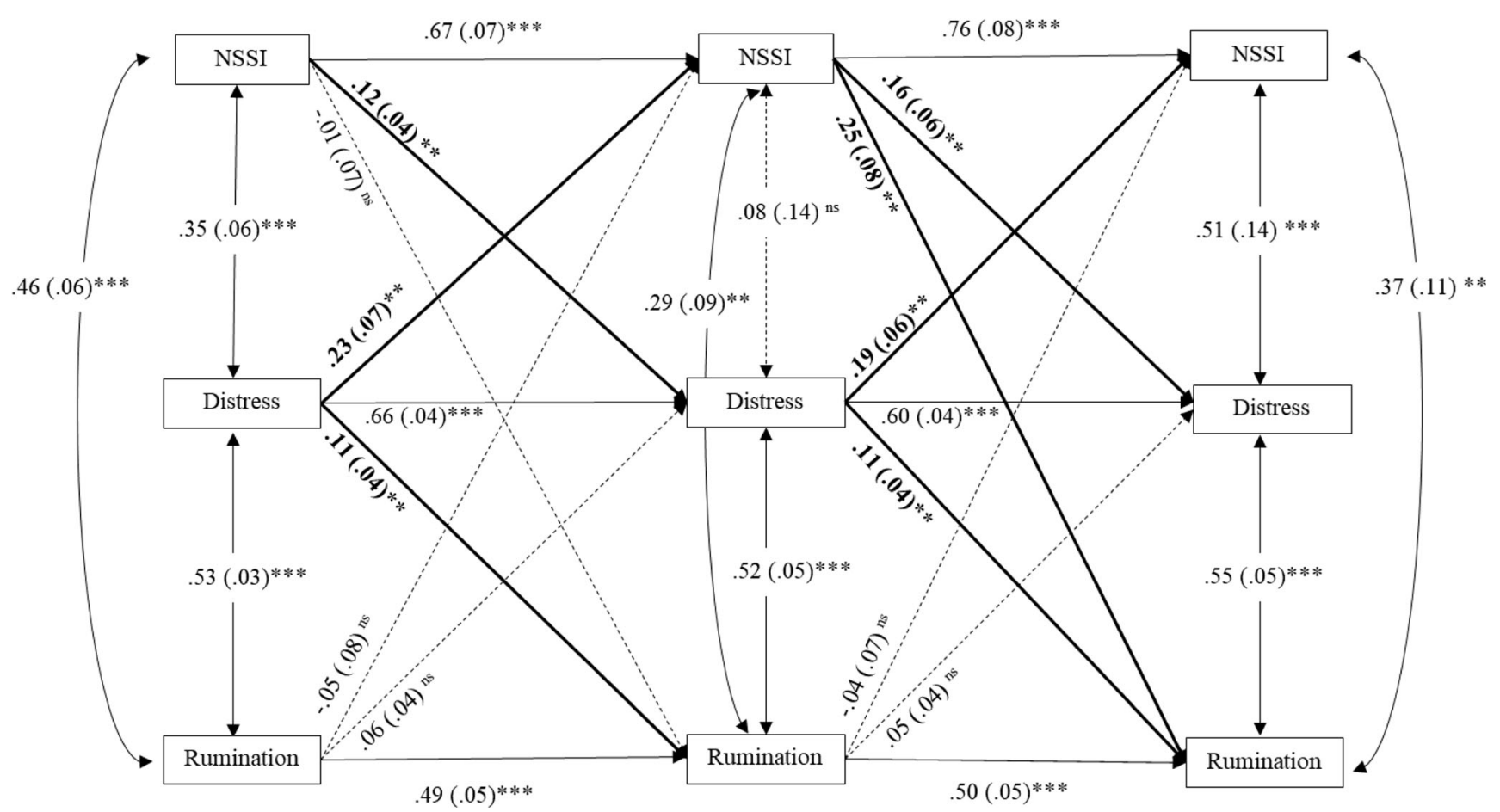

Fig. 2 Constrained cross-lagged path model linking NSSI, Distress, and Rumination, with standardised path coefficients and standard errors. * $p<0.05$; $* * p<0.01 ; * * * p<0.001$

in a rejecting or condemning manner (Crouch and Wright 2004; Favazza 1998; Gratz 2003). Consequently, these reactions could damage close relationships and increase the amount of interpersonal stress, which, in turn, could lead to depressive symptoms due to isolation and loneliness. Research by Burke and colleagues (Burke et al. 2015) has indeed shown that, for late adolescent girls, NSSI frequency predicted the occurrence of interpersonal stressful life events one year later.

Second, we suggested impaired emotion regulation as another possible explanation of NSSI leading to later distress. Recently, Robinson and colleagues (Robinson et al. 2018) reported that NSSI can be considered as a risk factor for poorer emotion regulation skills one year later in adolescents. As individuals may rely upon NSSI to quickly regulate their distress (Chapman et al. 2006), they are increasingly less exposed to intense emotions and more adaptive strategies to handle heightened distress. Consequently, they may start perceiving psychological distress as something unbearable (Robinson et al. 2018) or might perceive that they lack the ability to effectively regulate emotion (Kiekens et al. 2017) which could explain NSSI preceding increased self-reported distress such as found in the current study.

Several neurobiological studies yielded support for altered emotion regulation processes in adolescents with NSSI (Brown and Plener 2017; Plener et al. 2018). For instance, an altered pattern of the hypothalamic-pituitary adrenocortical axis (HPA; a major stress response system of the human body) regulation was found among adolescents engaging in NSSI compared to an age- and gender matched healthy control group (Reichl et al. 2016). Mechanisms such as resentment regarding scars, interpersonal stressors, or impaired emotion regulation should be taken into account by future longitudinal studies in order to further unravel the dynamic relationship between NSSI and distress.

\section{NSSI and Rumination}

The correlated change analyses indicated that increases in rumination were accompanied by increases in NSSI. Crosslagged path analysis, however, indicated that NSSI predicted rumination over the second, but not the first time interval. These inconsistent findings might be ascribed to the way NSSI was operationalised at T1 (i.e., lifetime prevalence) compared to T2 and T3 (i.e., 12-month prevalence), and suggest that only those with recent NSSI engagement (i.e., including new onset and persistent cases), and probably not those who ceased the behaviour, are at risk for increased rumination one year later. Nonetheless, this unidirectional pathway (i.e., recent NSSI predicting rumination) could be an important piece to the puzzle of long-term NSSI engagement. However, to the best of our knowledge, no research to date has reported similar findings. We suggest a number of interpretations to pave the way for future research. 
First, NSSI could be considered as a means of thought suppression, a deliberate attempt not to ruminate or think about something (Najmi et al. 2007; Wegner 1989). Selby and Joiner (Selby and Joiner 2009) theorised that the longterm effect of thought suppression may be more rumination, thus possibly resulting in NSSI preceding increased rumination over time. Indeed, a meta-analysis by Abramowitz et al. (2001) suggested that, following such efforts to suppress unwanted thoughts, the frequency of these thoughts actually 'rebounds' to a much higher frequency. This rebound effect takes places almost immediately after thought suppression (Wenzlaff and Wegner 2000), but is still measurable up to seven days afterwards (Geraerts et al. 2006). It might be the case that long-term engagement in NSSI induces a long-term alteration in rumination, which remains measurable for a much longer timespan than originally thought.

Second, ruminating about NSSI itself might be another possible explanation of the unidirectional NSSI-rumination pathway found in the present study. Qualitative research has shown that young people are well aware that NSSI is a maladaptive coping behaviour which, ideally, should be abandoned (Kelada et al. 2018). However, they also experience the effectiveness of NSSI in relieving their distress and therefore do not want to let go of the NSSI. The inner struggle created by these conflicting feelings can lead to ambivalent and ruminative thoughts. Individuals who engage in NSSI commonly reported they were unable to stop reflecting upon NSSI (Kelada et al. 2018) and repeatedly questioned whether they would ever stop thinking about hurting themselves or having the urge to hurt themselves (Victor et al. 2015). In the current study, we did not measure the content of the adolescents' ruminative thoughts. However, it seems that NSSI provides adolescents with a highly salient topic to ruminate upon (Victor et al. 2015), which might explain why NSSI predicted future rumination.

Third, each time adolescents engage in NSSI to alleviate distressing thoughts, they miss an opportunity to use an adaptive coping method such as problem-solving thinking or social support seeking (Andover et al. 2007). Therefore, adolescents with NSSI get less practice with adaptive coping styles and will have less access to helpful cognitive skills when under distress (Dear et al. 2001; Nock and Mendes 2008), which could explain the association between rumination -a maladaptive coping mechanism- and NSSI.

\section{Psychological Distress and Rumination}

Most previous findings (Abela and Hankin 2011; NolenHoeksema et al. 1992; Thomsen 2006) showed prospective bidirectional distress-rumination associations. Conversely, our cross-lagged analyses revealed only a unidirectional association between distress and rumination over time (i.e., distress leading to rumination but not vice versa). The fact that we did not find the bidirectional association, might be ascribed to the strict statistical approach used for the cross-lagged analyses in the current study (Klimstra et al. 2010, 2012). Namely, the large amount of control paths leaves less variance to be explained by the cross-lagged paths (Cui et al. 2007). The correlated change analyses, however, did show increases in distress being significantly related to increases in rumination. This indicates that, in the current study, distress and rumination were related constructs that seemed to develop together.

\section{NSSI Embedded in an Emotional-Cognitive Network}

Taking these results together, we can embed NSSI in a broader network of emotional and cognitive antecedents and consequents. Namely, distress predicts both NSSI and rumination over time, and NSSI, in turn, predicts distress and rumination (in the second interval) over time. Recent theoretical longitudinal models have integrated these concepts into one comprehensive framework. For instance, the Cognitive-Emotional Model of NSSI (CEM-NSSI) was recently developed by Hasking et al. (2017). In the CEM-NSSI, both emotional and cognitive processes are highlighted that work in concert to govern NSSI (Hasking et al. 2017). However, CEM-NSSI as a model focuses on why some people engage in NSSI and why others use more adaptive emotion regulation strategies. In interpreting our prospective findings regarding NSSI, the earlier mentioned Emotional Cascade Model (ECM; Selby et al. 2008) can be more helpful. In the ECM, NSSI is used as an immediate, momentary escape from the intense emotionrumination cycle. Supporting this theory, we found positive within-time associations between NSSI, distress, and rumination in the current study. However, this merely shows that all three concepts co-occur at one moment in time. The focus of the current study were the longitudinal associations between NSSI, distress, and rumination. Our longitudinal data showed that NSSI plays a significant part in increasing distress and rumination over time and thus could sustain the emotional cascade of distress and rumination. This advocates extending short-term models such as ECM with a long-term component (i.e., prospective pathways from NSSI to emotional and cognitive consequences). Some authors have already attempted to bridge longitudinal research and the ECM. For instance, Selby and Joiner (2009) theorised that one emotional cascade may lead to another, a process referred to as "circular causality" (Haken 1977). Circular causality happens because the dysregulated behaviour that is used to initially escape the emotional cascade actually triggers negative emotion in itself. Although Selby and Joiner focused on patients with borderline personality disorder, circular causality may essentially make understandable why some adolescents engage in repetitive NSSI. Specifically, if NSSI is used to escape the distress-rumination cycle, but subsequently also triggers ruminative thoughts, a 
new cascade may be initiated. As such, new cascades of distress and rumination may keep on arising and -if not adequately treated or prevented- distress, rumination, and NSSI might keep on reinforcing one another over time.

\section{Limitations and Future Research Directions}

Although the present study provided incremental understanding of the directionality of effects linking psychological distress, rumination and NSSI, our study is not without limitations. First, the number of cases engaging in NSSI at T2 and $\mathrm{T} 3$ is low, which leaves us with limited power and possibly an inability to detect some significant results. Further research in larger samples is therefore recommended. Second, we based our findings on adolescent self-report questionnaires. Collecting self-report data from a single informant could result in reporting bias and shared method variance (Podsakoff et al. 2003). A multiple informant approach would expand our understanding on the associations between NSSI, distress, and rumination. However, research has shown that people do not always observe internalising behaviours accurately in others (e.g., Achenbach et al. 1987), making psychological distress and rumination difficult to be assessed by other informants. Similarly, NSSI is often secretive (Baetens et al. 2011) and people close to the self-injurer, such as parents, are very often not aware of the NSSI that is going on (Baetens et al. 2015). Furthermore, shared method variance is accounted for in cross-lagged analyses by controlling for all within-time associations and stability of each variable over time (Orth et al. 2008). Third, in studying the associations between distress, rumination, and NSSI, we solely focused on the prevalence of NSSI (lifetime prevalence at T1 and 12-month prevalence at T2/T3). It would be insightful if further research would examine whether certain NSSI severity indicators (i.e., number of methods, NSSI frequency, NSSI disorder; APA 2013) have an impact on the strength of the reported associations. Relatedly, by using a variable-centred approach, we may be obscuring potential meaningful differences between different patterns of NSSI (i.e., new onset, desisting, relapsing, persistent). Future research using a person-centred approach could improve our understanding about NSSI patterns and their associations with emotional and cognitive factors over time. Fourth, because the present study primarily sampled Caucasian European secondary school students, we might have missed possible cultural differences. However, a recent review reported many areas of similarities in NSSI features between non-Western and Western cultures: prevalence rates of NSSI, age of NSSI onset, associations with suicidal behaviour, and risk factors (e.g., depression, childhood maltreatment) were very similar across cultures (Gholamrezaei et al. 2017). Nevertheless, findings of the current study cannot be directly generalised to non-Caucasian samples or more diverse Western samples and future research should investigate if the interrelations of NSSI, distress, and rumination persist across cultures. Fifth, we deliberately chose to conduct our study in community adolescents and our results show the centrality of NSSI as a mental health concern among this group. However, further research needs to explore the interplay between NSSI, distress, and rumination in a clinical sample. Longitudinal research in a patient population could inform us if the long-term vicious cycle of NSSI, distress, and rumination found in our community sample of adolescents is more pronounced among those experiencing higher levels of psychopathology. Finally, it is possible that there are unmeasured variables operating on NSSI, rumination, and/or distress. For instance, common factors of our study variables include neuroticism, trauma, distorted emotion regulation, or borderline personality disorder features (Gratz 2003; Perlman et al. 2018; Selby and Joiner 2009). Including these additional factors in future research would allow us to make more precise estimations of the variance explained by the interplay between NSSI, distress, and rumination.

\section{Conclusion}

Despite these limitations, the present study adds to the research literature by (a) embedding NSSI in a broader network of cognitive and emotional antecedents and consequents, and (b) considering the long-term influence these components exert on each other. Awaiting further research, our findings have potential clinical implications. For instance, to treat NSSI and possibly prevent relapse, it may be important to not only pay attention to the emotional and cognitive antecedents triggering NSSI. Clinicians should also take into account that engaging in NSSI may have detrimental consequences on the psychological state of adolescents over time, by increasing both rumination and psychological distress. This increased awareness of consequents -next to antecedentsof behaviour is well implemented in Dialectical Behaviour Therapy (DBT). In DBT, sequential events before and after a certain behaviour are combined in a so-called chain analysis (Lynch et al. 2006). Several studies provided evidence for the effectivity of DBT in reducing the frequency of self-harm with or without suicidal intent (e.g., Koons et al. 2001; Linehan et al. 2002). Furthermore, a systematic review demonstrated that capturing antecedents and consequents in functional assessments is a typical feature of an effective therapy for NSSI (Turner et al. 2014). In sum, although NSSI provides short-term relief to the build-up cycle of distress and rumination, our research showed that, over time, NSSI may play a significant part in increasing distress and rumination, which potentially sustains a longer-term maladaptive cycle between emotion, cognition, and NSSI. 
Acknowledgements This study was funded by Fonds Wetenschappelijk Onderzoek (FWO, Belgium; grant number G062117 N).

\section{Compliance with Ethical Standards}

Conflict of Interest The authors declare that they have no conflict of interest.

\section{References}

Abela, J. R. Z., \& Hankin, B. L. (2011). Rumination as a vulnerability factor to depression during the transition from early to middle adolescence: A multiwave longitudinal study. Journal of Abnormal Psychology, 120(2), 259-271. https://doi.org/10.1037/a0022796.

Abramowitz, J. S., Tolin, D. F., \& Street, G. P. (2001). Paradoxical effects of thought suppression: A meta-analysis of controlled studies. Clinical Psychology Review, 21(5), 683-703. https://doi.org/10. 1016/S0272-7358(00)00057-X.

Achenbach, T. M., McConaughy, S. H., \& Howell, C. T. (1987). Child/ adolescent behavioral and emotional problems: Implications of cross-informant correlations for situational specificity. Psychological Bulletin, 101(2), 213-232. https://doi.org/10.1037/ 0033-2909.101.2.213.

Alloy, L. B., Hamilton, J. L., Hamlat, E. J., \& Abramson, L. Y. (2016). Pubertal development, emotion regulatory styles, and the emergence of sex differences in internalizing disorders and symptoms in adolescence. Clinical Psychological Science, 4(5), 867-881. https://doi.org/10.1177/2167702616643008.

American Psychiatric Association. (2013). Diagnostic and statistical manual of mental disorders (pp. DSM-DS5). Washington DC: American Psychiatric Press.

Anderson, T. N., \& Kida, T. E. (1982). The cross-lagged research approach: Description and illustration. Journal of Accounting Research, 20(2), 403. https://doi.org/10.2307/2490748.

Andover, M. S., Pepper, C. M., \& Gibb, B. E. (2007). Self-mutilation and coping strategies in a college sample. Suicide and Life-threatening Behavior, 37(2), 238-243. https://doi.org/10.1521/suli.2007.37.2.238.

Armey, M. F., \& Crowther, J. H. (2008). A comparison of linear versus non-linear models of aversive self-awareness, dissociation, and nonsuicidal self-injury among young adults. Journal of Consulting and Clinical Psychology, 76(1), 9-14. https://doi.org/10.1037/0022006X.76.1.9.

Baetens, I., Claes, L., Muehlenkamp, J., Grietens, H., \& Onghena, P. (2011). Non-suicidal and suicidal self-injurious behavior among flemish adolescents: A web-survey. Archives of Suicide Research, 15(1), 56-67. https://doi.org/10.1080/13811118.2011.540467.

Baetens, I., Claes, L., Onghena, P., Grietens, H., Van Leeuwen, K., Pieters, C., ... Griffith, J. W. (2015). The effects of nonsuicidal self-injury on parenting behaviors: A longitudinal analyses of the perspective of the parent. Child and Adolescent Psychiatry and Mental Health, 9(1). https://doi.org/10.1186/s13034-015-0059-2

Barrocas, A. L., Giletta, M., Hankin, B. L., Prinstein, M. J., \& Abela, J. R. Z. (2015). Nonsuicidal self-injury in adolescence: Longitudinal course, trajectories, and intrapersonal predictors. Journal of Abnormal Child Psychology, 43(2), 369-380. https://doi.org/10. 1007/s10802-014-9895-4.

Bjärehed, J., \& Lundh, L. (2008). Deliberate self-harm in 14-year-old adolescents: How frequent is it, and how is it associated with psychopathology, relationship variables, and styles of emotional regulation? Cognitive Behaviour Therapy, 37(1), 26-37. https://doi.org/10.1080/16506070701778951.

Brown, T. A. (2015). Confirmatory factor analysis for applied research (Second ed.). New York: The Guildford Press.

Brown, R. C., \& Plener, P. L. (2017). Non-suicidal self-injury in adolescence. Current Psychiatry Reports, 19. https://doi.org/10.1007/ s11920-017-0767-9.

Burke, T. A., Hamilton, J. L., Abramson, L. Y., \& Alloy, L. B. (2015). Non-suicidal self-injury prospectively predicts interpersonal stressful life events and depressive symptoms among adolescent girls. Psychiatry Research, 228(3), 416-424. https://doi.org/10.1016/j. psychres.2015.06.021.

Carlin, J. B. (2015). Multiple imputation: A perspective and historical overview. In A. A. Tsiatis, M. G. Kenward, G. Fitzmaurice, G. Verbeke, \& G. Molenberghs (Eds.), Handbook of missing data. New York: Taylor \& Francis.

Cassels, M., \& Wilkinson, P. (2016). Non-suicidal self-injury in adolescence. Paediatrics and Child Health, 26(12), 554-558. https://doi.org/10.1016/j.paed.2016.08.006.

Chan, Y.-F., Leung, D. Y. P., Fong, D. Y. T., Leung, C.-M., \& Lee, A. M. (2010). Psychometric evaluation of the hospital anxiety and depression scale in a large community sample of adolescents in Hong Kong. Quality of Life Research, 19(6), 865-873. https://doi.org/10. 1007/s11136-010-9645-1.

Chapman, A. L., Gratz, K. L., \& Brown, M. Z. (2006). Solving the puzzle of deliberate self-harm: The experiential avoidance model. Behaviour Research and Therapy, 44(3), 371-394. https://doi.org/ 10.1016/j.brat.2005.03.005.

Crouch, W., \& Wright, J. (2004). Deliberate self-harm at an adolescent unit: A qualitative investigation. Clinical Child Psychology and Psychiatry, 9(2), 185-204. https://doi.org/ 10.1177/1359104504041918.

Cui, M., Donnellan, M. B., \& Conger, R. D. (2007). Reciprocal influences between parents' marital problems and adolescent internalizing and externalizing behavior. Developmental Psychology, 43(6), 1544-1552. https://doi.org/10.1037/0012-1649.43.6.1544.

Davey, C. G., Yücel, M., \& Allen, N. B. (2008). The emergence of depression in adolescence: Development of the prefrontal cortex and the representation of reward. Neuroscience and Biobehavioral Reviews, 32(1), 1-19. https://doi.org/10.1016/ j.neubiorev.2007.04.016.

Dear, G. E., Slattery, J. L., \& Hillan, R. J. (2001). Evaluations of the quality of coping reported by prisoners who have self-harmed and those who have not. Suicide \& Life-Threatening Behavior, 31(4), $442-450$

Donaldson, C., \& Lam, D. (2004). Rumination, mood and social problem-solving in major depression. Psychological Medicine, 34(7), 1309-1318. https://doi.org/10.1017/S0033291704001904.

Favazza, A. R. (1998). The coming of age of self-mutilation. The Journal of Nervous \& Mental Disease, 186(5), 259-268. https://doi.org/10. 1097/00005053-199805000-00001.

Franklin, J. C., Hessel, E. T., Aaron, R. V., Arthur, M. S., Heilbron, N., \& Prinstein, M. J. (2010). The functions of nonsuicidal self-injury: Support for cognitive-affective regulation and opponent processes from a novel psychophysiological paradigm. Journal of Abnormal Psychology, 119(4), 850-862. https://doi.org/10.1037/a0020896.

Gandhi, A., Luyckx, K., Maitra, S., \& Claes, L. (2016). Non-suicidal selfinjury and other self-directed violent behaviors in India: A review of definitions and research. Asian Journal of Psychiatry, 22(2015), 196-201. https://doi.org/10.1016/j.ajp.2015.09.015.

Gandhi, A., Luyckx, K., Maitra, S., Kiekens, G., Verschueren, M., \& Claes, L. (2017). Directionality of effects between non-suicidal self-injury and identity formation: A prospective study in adolescents. Personality and Individual Differences, 109, 124-129. https://doi.org/10.1016/j.paid.2017.01.003. 
Gandhi, A., Luyckx, K., Baetens, I., Kiekens, G., Sleuwaegen, E., Berens, A., Maitra, S., \& Claes, L. (2018). Age of onset of nonsuicidal self-injury in Dutch-speaking adolescents and emerging adults: An event history analysis of pooled data. Comprehensive Psychiatry, 80, 170-178. https://doi.org/10.1016/j.comppsych. 2017.10.007.

Geraerts, E., Merckelbach, H., Jelicic, M., \& Smeets, E. (2006). Long term consequences of suppression of intrusive anxious thoughts and repressive coping. Behaviour Research and Therapy, 44(10), 14511460. https://doi.org/10.1016/j.brat.2005.11.001.

Gholamrezaei, M., De Stefano, J., \& Heath, N. L. (2017). Nonsuicidal self-injury across cultures and ethnic and racial minorities: A review. International Journal of Psychology, 52(4), 316-326. https://doi.org/10.1002/ijop.12230.

Gratz, K. L. (2003). Risk factors for and functions of deliberate self-harm: An empirical and conceptual review. Clinical Psychology: Science and Practice, 10(2), 192-205. https://doi.org/10.1093/clipsy/ $\operatorname{bpg} 022$.

Haavisto, A., Sourander, A., Multimäki, P., Parkkola, K., Santalahti, P., Helenius, H., Nikolakaros, G., Moilanen, I., Kumpulainen, K., Piha, J., Aronen, E., Puura, K., Linna, S. L., \& Almqvist, F. (2005). Factors associated with ideation and acts of deliberate self-harm among 18-year-old boys. Social Psychiatry and Psychiatric Epidemiology, 40(11), 912-921. https://doi.org/10.1007/s00127005-0966-2.

Haken, H. (1977). Synergetics - an introduction. Nonequilibrium phase transitions and self-organization in physics, chemistry, and biology. Berlin: Springer-Verlag.

Hankin, B. L., \& Abela, J. R. Z. (2011). Nonsuicidal self-injury in adolescence: Prospective rates and risk factors in a $2 \frac{1}{2} 2$ year longitudinal study. Psychiatry Research, 186(1), 65-70. https://doi.org/10.1016/ j.psychres.2010.07.056.

Hankin, B. L., \& Abramson, L. Y. (2001). Development of gender differences in depression: An elaborated cognitive vulnerabilitytransactional stress theory. Psychological Bulletin, 127(6), 773796. https://doi.org/10.1037/0033-2909.127.6.773.

Harrell, F. E. J. (2001). Regression modeling strategies. New York: Springer-Verlag.

Hasking, P., Whitlock, J., Voon, D., \& Rose, A. (2017). A cognitiveemotional model of NSSI: Using emotion regulation and cognitive processes to explain why people self-injure. Cognition and Emotion, 31(8), 1543-1556. https://doi.org/10.1080/02699931.2016. 1241219.

Hilt, L. M., McLaughlin, K. A., \& Nolen-Hoeksema, S. (2010). Examination of the response styles theory in a community sample of young adolescents. Journal of Abnormal Child Psychology, 38(4), 545-556. https://doi.org/10.1007/s10802-009-9384-3.

Hodgson, S. (2004). Cutting through the silence: A sociological construction of self-injury. Sociological Inquiry, 74(2), 162179. https://doi.org/10.1111/j.1475-682X.2004.00085.x.

Hoff, E. R., \& Muehlenkamp, J. J. (2009). Nonsuicidal self-injury in college students: The role of perfectionism and rumination. Suicide and Life-threatening Behavior, 39(6), 576-587. https://doi.org/10.1521/suli.2009.39.6.576.

Jose, P. E., \& Brown, I. (2008). When does the gender difference in rumination begin? Gender and age differences in the use of rumination by adolescents. Journal of Youth and Adolescence, 37(2), 180 192. https://doi.org/10.1007/s10964-006-9166-y.

Jose, P. E., \& Weir, K. F. (2013). How is anxiety involved in the longitudinal relationship between brooding rumination and depressive symptoms in adolescents? Journal of Youth and Adolescence, 42(8), 1210-1222. https://doi.org/10.1007/ s10964-012-9891-3.

Kelada, L., Hasking, P., Melvin, G., Whitlock, J., \& Baetens, I. (2018). "I do want to stop, at least I think I do": An international comparison of recovery from nonsuicidal self-injury among young people. Journal of Adolescent Research, 33(4), 416-441. https://doi.org/10.1177/ 0743558416684954

Kiekens, G., Hasking, P., Bruffaerts, R., Claes, L., Baetens, I., Boyes, M., Mortier, P., Demyttenaere, K., \& Whitlock, J. (2017). What predicts ongoing nonsuicidal self-injury? The Journal of Nervous and Mental Disease, 205(10), 762-770. https://doi.org/10.1097/NMD. 0000000000000726.

Klimstra, T. A., Akse, J., Hale, W. W., Raaijmakers, Q. A. W., \& Meeus, W. H. J. (2010). Longitudinal associations between personality traits and problem behavior symptoms in adolescence. Journal of Research in Personality, 44(2), 273-284. https://doi.org/10.1016/j. jrp.2010.02.004.

Klimstra, T. A., Luyckx, K., Germeijs, V., Meeus, W. H. J., \& Goossens, L. (2012). Personality traits and educational identity formation in late adolescents: Longitudinal associations and academic progress. Journal of Youth and Adolescence, 41(3), 346-361. https://doi.org/ 10.1007/s10964-011-9734-7.

Kline, R. B. (2005). Principles and practice of structural equation modeling. New York: Guildford Press.

Klonsky, E. D., Victor, S. E., \& Saffer, B. Y. (2014). Nonsuicidal selfinjury: What we know, and what we need to know. The Canadian Journal of Psychiatry, 59(11), 565-568. https://doi.org/10.1177/ 070674371405901101.

Koons, C. R., Robins, C. J., Lindsey Tweed, J., Lynch, T. R., Gonzalez, A. M., Morse, J. Q., Bishop, G. K., Butterfield, M. I., \& Bastian, L. A. (2001). Efficacy of dialectical behavior therapy in women veterans with borderline personality disorder. Behavior Therapy, 32, 371-390. https://doi.org/10.1016/S0005-7894(01)80009-5.

Lewis, S. P. (2016). The overlooked role of self-injury scars: Commentary and suggestions for clinical practice. Journal of Nervous and Mental Disease, 204(1), 33-35. https://doi.org/10. 1097/NMD.0000000000000436.

Lewis, S. P., \& Mehrabkhani, S. (2016). Every scar tells a story: Insight into people's self-injury scar experiences. Counselling Psychology Quarterly, 29(3), 296-310. https://doi.org/10.1080/09515070.2015. 1088431.

Linehan, M. M., Dimeff, L. A., Reynolds, S. K., Comtois, K. A., Welch, S. S., Heagerty, P., \& Kivlahan, D. R. (2002). Dialectical behavior therapy versus comprehensive validation therapy plus 12-step for the treatment of opioid dependent women meeting criteria for borderline personality disorder. Drug and Alcohol Dependence, 67(1), 13-26. https://doi.org/10.1016/S0376-8716(02)00011-X.

Lundh, L., Wångby-Lundh, M., \& Bjärehed, J. (2011a). Deliberate selfharm and psychological problems in young adolescents: Evidence of a bidirectional relationship in girls. Scandinavian Journal of Psychology, 52(5), 476-483. https://doi.org/10.1111/j.1467-9450. 2011.00894.x.

Lundh, L.-G., Wångby-Lundh, M., Paaske, M., Ingesson, S., \& Bjärehed, J. (2011b). Depressive symptoms and deliberate self-harm in a community sample of adolescents: A prospective study. Depression Research and Treatment, 2011,1-11. https://doi.org/10.1155/2011/ 935871.

Lynch, T. R., Chapman, A. L., Rosenthal, M. Z., Kuo, J. R., \& Linehan, M. M. (2006). Mechanisms of change in dialectical behavior therapy: Theoretical and empirical observations. Journal of Clinical Psychology, 62(4), 459-480. https://doi.org/10.1002/jclp.20243.

Mahtani, S., Melvin, G. A., \& Hasking, P. (2018). Shame proneness, shame coping, and functions of nonsuicidal self-injury (NSSI) among emerging adults. Emerging Adulthood, 6(3), 159-171. https://doi.org/10.1177/2167696817711350.

Marshall, S. K., Tilton-Weaver, L. C., \& Stattin, H. (2013). Non-suicidal self-injury and depressive symptoms during middle adolescence: A longitudinal analysis. Journal of Youth and Adolescence, 42(8), 1234-1242. https://doi.org/10.1007/s10964-013-9919-3.

McIntosh, W. D. (1996). When does goal nonattainment lead to negative emotional reactions, and when doesn't it? The role of linking and 
rumination. In L. L. Martin \& A. Tesser (Eds.), Striving and feeling. Interactions among goals, affect, and self-regulation (pp. 53-77). Mahwah: Erlbaum.

Messer, J. M., \& Fremouw, W. J. (2008). A critical review of explanatory models for self-mutilating behaviors in adolescents. Clinical Psychology Review, 28(1), 162-178. https://doi.org/10.1016/j.cpr. 2007.04.006

Muehlenkamp, J. J., \& Brausch, A. M. (2012). Body image as a mediator of non-suicidal self-injury in adolescents. Journal of Adolescence, 35(1), 1-9. https://doi.org/10.1016/j.adolescence.2011.06.010.

Muehlenkamp, J. J., Claes, L., Havertape, L., \& Plener, P. L. (2012). International prevalence of adolescent non-suicidal self-injury and deliberate self-harm. Child and Adolescent Psychiatry and Mental Health, 6(1), 10. https://doi.org/10.1186/1753-2000-6-10.

Muthén, L. K., \& Muthén, B. O. (2012). Mplus: The comprehensive modeling program for applied researchers: User's guide. Los Angeles, CA: Muthén \& Muthén.

Muthén, L. K., \& Muthén, B. O. (2017). Mplus User's guide. Eighth edition. Los Angeles, CA: Muthén \& Muthén. https://doi.org/10. 1111/j.1600-0447.2011.01711.x.

Najmi, S., Wegner, D. M., \& Nock, M. K. (2007). Thought suppression and self-injurious thoughts and behaviors. Behaviour Research and Therapy, 45(8), 1957-1965. https://doi.org/10.1016/j.brat.2006.09.014.

Nock, M. K. (2009). Why do people hurt themselves? Current Directions in Psychological Science, 18(2), 78-83. https://doi.org/10.1111/j. 1467-8721.2009.01613.x.

Nock, M. K., \& Cha, C. (2009). Psychological models of non-suicidal self-injury. In In Understanding nonsuicidal self-injury: Origins, assessment and treatment. Washington DC: American Psychological Association.

Nock, M. K., \& Favazza, A. R. (2009). Nonsuicidal self-injury: Definition and classification. In Understanding nonsuicidal self-injury: Origins, assessment, and treatment (pp. 9-18). Washington: American Psychological Association. https://doi.org/10.1037/ 11875-001.

Nock, M. K., \& Mendes, W. B. (2008). Physiological arousal, distress tolerance, and social problem-solving deficits among adolescent self-injurers. Journal of Consulting and Clinical Psychology, 76(1), 28-38. https://doi.org/10.1037/0022-006X.76.1.28.

Nock, M. K., \& Prinstein, M. J. (2005). Contextual features and behavioral functions of self-mutilation among adolescents. Journal of Abnormal Psychology, 114(1), 140-146. https://doi.org/10.1037/ 0021-843X.114.1.140.

Nock, M. K., Joiner, T. E., Gordon, K. H., Lloyd-Richardson, E., \& Prinstein, M. J. (2006). Non-suicidal self-injury among adolescents: Diagnostic correlates and relation to suicide attempts. Psychiatry Research, 144(1), 65-72. https://doi.org/ 10.1016/j.psychres.2006.05.010

Nolen-Hoeksema, S., Girgus, J. S., \& Seligman, M. E. (1992). Predictors and consequences of childhood depressive symptoms: A 5-year longitudinal study. Journal of Abnormal Psychology, 101(3), 405-422. https://doi.org/10.1037/0021-843X.101.3.405.

Nolen-Hoeksema, S., Wisco, B. E., \& Lyubomirsky, S. (2008). Rethinking rumination. Perspectives on Psychological Science, 3(5), 400-424. https://doi.org/10.1111/j.1745-6924.2008.00088.x.

Norton, S., Cosco, T., Doyle, F., Done, J., \& Sacker, A. (2013). The hospital anxiety and depression scale: A meta confirmatory factor analysis. Journal of Psychosomatic Research, 74(1), 74-81. https://doi.org/10.1016/j.jpsychores.2012.10.010.

Orth, U., Robins, R. W., \& Roberts, B. W. (2008). Low self-esteem prospectively predicts depression in adolescence and young adulthood. Journal of Personality and Social Psychology, 95(3), 695708. https://doi.org/10.1037/0022-3514.95.3.695.

Perlman, G., Gromatsky, M., Salis, K. L., Klein, D. N., \& Kotov, R. (2018). Personality correlates of self-injury in adolescent girls: Disentangling the effects of lifetime psychopathology. Journal of
Abnormal Child Psychology, 46, 1-9. https://doi.org/10.1007/ s10802-018-0403-0.

Plener, P. L., Schumacher, T. S., Munz, L. M., \& Groschwitz, R. C. (2015). The longitudinal course of non-suicidal self-injury and deliberate self-harm: A systematic review of the literature. Borderline Personality Disorder and Emotion Dysregulation, 2(1), 2. https:// doi.org/10.1186/s40479-014-0024-3.

Plener, P. L., Kaess, M., Schmahl, C., Pollak, S., Fegert, J. M., \& Brown, R. C. (2018). Nonsuicidal self-injury in adolescents. Deutsches Aerzteblatt Online, 23-30. https://doi.org/10.3238/ arztebl.2018.0023.

Podsakoff, P. M., MacKenzie, S. B., Lee, J.-Y., \& Podsakoff, N. P. (2003). Common method biases in behavioral research: A critical review of the literature and recommended remedies. Journal of Applied Psychology, 88(5), 879-903. https://doi. org/10.1037/0021-9010.88.5.879.

Reichl, C., Heyer, A., Brunner, R., Parzer, P., Völker, J. M., Resch, F., \& Kaess, M. (2016). Hypothalamic-pituitaryadrenal axis, childhood adversity and adolescent nonsuicidal self-injury. Psychoneuroendocrinology, 74, 203-211. https:// doi.org/10.1016/j.psyneuen.2016.09.011.

Robinson, K., Garisch, J. A., Kingi, T., Brocklesby, M., O’Connell, A., Langlands, R. L., Russell, L., \& Wilson, M. S. (2018). Reciprocal risk: The longitudinal relationship between emotion regulation and non-suicidal self-injury in adolescents. Journal of Abnormal Child Psychology., 47, 325-332. https://doi.org/10.1007/s10802-0180450-6.

Rodríguez-Blanco, L., Carballo, J. J., \& Baca-García, E. (2018). Use of ecological momentary assessment (EMA) in non-suicidal self-injury (NSSI): A systematic review. Psychiatry Research, 263(2017), 212219. https://doi.org/10.1016/j.psychres.2018.02.051.

Ross, S., Heath, N. L., \& Toste, J. R. (2009). Non-suicidal self-injury and eating pathology in high school students. American Journal of Orthopsychiatry, 79(1), 83-92. https://doi.org/10.1037/a0014826.

Rubin, D. B. (2004). Multiple imputation for nonresponse in surveys. New York: John Wiley \& Sons.

Selby, E. A., \& Joiner, T. E. (2009). Cascades of emotion: The emergence of borderline personality disorder from emotional and behavioral dysregulation. Review of General Psychology, 13(3), 219-229. https://doi.org/10.1037/a0015687.

Selby, E. A., Anestis, M. D., \& Joiner, T. E. (2008). Understanding the relationship between emotional and behavioral dysregulation: Emotional cascades. Behaviour Research and Therapy, 46(5), 593-611. https://doi.org/10.1016/j.brat.2008.02.002.

Selby, E. A., Connell, L. D., \& Joiner, T. E. (2010). The pernicious blend of rumination and fearlessness in non-suicidal self-injury. Cognitive Therapy and Research, 34(5), 421-428. https://doi.org/10.1007/ s10608-009-9260-z.

Selby, E. A., Franklin, J., Carson-Wong, A., \& Rizvi, S. L. (2013). Emotional cascades and self-injury: Investigating instability of rumination and negative emotion. Journal of Clinical Psychology, 69(12), 1213-1227. https://doi.org/10.1002/jclp.21966.

Silvers, J. a., McRae, K., Gabrieli, J. D. E., Gross, J. J., Remy, K. a., \& Ochsner, K. N. (2012). Age-related differences in emotional reactivity, regulation, and rejection sensitivity in adolescence. Emotion, 12(6), 1235-1247. https://doi.org/10.1037/a0028297.

Sourander, A., Aromaa, M., Pihlakoski, L., Haavisto, A., Rautava, P., Helenius, H., \& Sillanpää, M. (2006). Early predictors of deliberate self-harm among adolescents. A prospective follow-up study from age 3 to age 15. Journal of Affective Disorders, 93(1-3), 87-96. https://doi.org/10.1016/j.jad.2006.02.015.

Stänicke, L. I., Haavind, H., \& Gullestad, S. E. (2018). How do young people understand their own self-harm? A meta-synthesis of adolescents' subjective experience of self-harm. Adolescent Research Review, 3(2), 173-191. https://doi.org/10.1007/s40894-018-0080-9. 
Swannell, S. V., Martin, G. E., Page, A., Hasking, P., \& St John, N. J. (2014). Prevalence of nonsuicidal self-injury in nonclinical samples: Systematic review, meta-analysis and meta-regression. Suicide and Life-threatening Behavior, 44(3), 273-303. https://doi.org/10.1111/ sltb. 12070.

Taylor, P. J., Jomar, K., Dhingra, K., Forrester, R., Shahmalak, U., \& Dickson, J. M. (2017). A meta-analysis of the prevalence of different functions of non-suicidal self-injury. Journal of Affective Disorders, 227, 759-769. https://doi.org/10.1016/j.jad.2017.11.073.

Thomsen, K. D. (2006). The association between rumination and negative affect: A review. Cognition \& Emotion, 20(8), 1216-1235. https://doi.org/10.1080/02699930500473533.

Trapnell, P. D., \& Campbell, J. D. (1999). Private self-consciousness and the five-factor model of personality: Distinguishing rumination from reflection. Journal of Personality and Social Psychology, 76(2), 284-304. https://doi.org/10.1037/0022-3514.76.2.284.

Turner, B. J., Austin, S. B., \& Chapman, A. L. (2014). Treating nonsuicidal self-injury: A systematic review of psychological and pharmacological interventions. The Canadian Journal of Psychiatry, 59(11), 576-585. https://doi.org/10.1177/ 070674371405901103.

Victor, S. E., Styer, D., \& Washburn, J. J. (2015). Characteristics of nonsuicidal self-injury associated with suicidal ideation:
Evidence from a clinical sample of youth. Child and Adolescent Psychiatry and Mental Health, 9(1), 20. https:// doi.org/10.1186/s13034-015-0053-8.

Wegner, D. M. (1989). White bears and other unwanted thoughts: Suppression, obsession, and the psychology of mental control. New York: Viking/Penguin.

Wenzlaff, R. M., \& Wegner, D. M. (2000). Thought suppression. In S. T. Fiske (Ed.), Annual review of psychology (pp. 55-91). Palo Alto: Annual Reviews.

White, D., Leach, C., Sims, R., Atkinson, M., \& Cottrell, D. (1983). Validation of the hospital anxiety and depression scale for use with adolescents. British Journal of Psychiatry, 175, 452-454.

Wilkinson, P., Kelvin, R., Roberts, C., Dubicka, B., \& Goodyer, I. (2011). Clinical and psychosocial predictors of suicide attempts and nonsuicidal self-injury in the adolescent depression antidepressants and psychotherapy trial (ADAPT). American Journal of Psychiatry, 168(5), 495-501. https://doi.org/10.1176/appi.ajp.2010.10050718.

Zigmond, A. S., \& Snaith, R. P. (1983). The hospital anxiety and depression scale. Acta Psychiatrica Scandinavica, 67(6), 361-370. https:// doi.org/10.1111/j.1600-0447.1983.tb09716.x.

Publisher's Note Springer Nature remains neutral with regard to jurisdictional claims in published maps and institutional affiliations. 